\title{
Improved stove programs need robust methods to estimate carbon offsets
}

\author{
Michael Johnson • Rufus Edwards • Omar Masera
}

Received: 3 February 2009 / Accepted: 30 September 2009 / Published online: 2 February 2010

(C) The Author(s) 2010. This article is published with open access at Springerlink.com

\begin{abstract}
Current standard methods result in significant discrepancies in carbon offset accounting compared to approaches based on representative community based subsamples, which provide more realistic assessments at reasonable cost. Perhaps more critically, neither of the currently approved methods incorporates uncertainties inherent in estimates of emission factors or non-renewable fuel usage (fNRB). Since emission factors and fNRB contribute $25 \%$ and $47 \%$, respectively, to the overall uncertainty in offset estimates for Purépecha communities in Mexico, exclusion of this uncertainty is a critical omission. When the recommended uncertainty for default emission factors and the uncertainty associated with regional estimates of fNRB are included the lower 95\% confidence intervals of both Clean Development Mechanism and Gold Standard methods exceed the total amount of carbon saved, which would result in zero marketable carbon savings if approaches recommended by the IPCC Good Practice Guidance and Uncertainty Management in National Greenhouse Gas Inventories, or Land use, Land-Use Change and Forestry (LULUCF) are to be followed. In contrast, for the same communities, methods using representative subsamples of emission factors and fuel consumption, combined with communitylevel fNRB estimates, result in significant carbon offsets with a lower $95 \%$ confidence interval of $2.3 \mathrm{tCO}_{2} \mathrm{e}$ home $\mathrm{e}^{-1}$ year ${ }^{-1}$. Given the misleading estimates, revision of the currently approved methodologies to provide robust estimates of carbon offsets is strongly recommended.
\end{abstract}

\footnotetext{
M. Johnson · R. Edwards ( $\varangle)$

Department of Epidemiology, School of Medicine, University of California, Irvine, 101 Theory, Suite 258, Irvine, CA 92697-3957, USA

e-mail: edwardsr@uci.edu

O. Masera

National Autonomous University of Mexico (UNAM), Morelia, Mexico
} 


\section{Introduction}

Carbon offsets from improved cookstove programs present an economic option in reduction of global carbon emissions especially given the large numbers of people relying on solid fuels for their primary energy provision, and the considerable health co-benefits that are incurred through reduction of air pollution. There are two currently applied standard methods for determination of carbon offsets from improved cookstoves: The Gold Standard "Methodology for Improved Cook-stoves and Kitchen Regimes" for voluntary markets (Climate Care 2008) and the "Switch from Non-Renewable Biomass for Thermal Applications by the User" small-scale CDM method for use under the Kyoto Protocol (UNFCCC 2008). Unfortunately, these methods follow neither the Guidelines for National Greenhouse Gas Inventories Tier III approach (Gomez and Watterson 2006) nor the Good Practice Guidance and Uncertainty Management in National Greenhouse Gas Inventories (IPCC 2000) by allowing non-representative inputs and not accounting for uncertainty in offset estimates. Given the adverse publicity over offset validity (Corre 2007; Harvey and Fidler 2007) and international scrutiny of carbon markets, use of these methods may ultimately undermine the carbon projects in the residential sector by eroding stakeholder confidence. Since methods for quantification of carbon offsets from improved stoves based on statistical sub-sampling on local community basis have been proposed that do not suffer from these drawbacks (Johnson et al. 2009), revision of the currently approved methodologies to provide robust offset estimates is warranted. This paper highlights the errors in carbon offset accounting that may be incurred using current standard methods and approaches that provide more realistic assessments at reasonable cost.

\section{Method comparison}

\subsection{Carbon offset estimation}

Schematically, carbon offsets for stove projects are defined as the difference in $\mathrm{CO}_{2}$-equivalent $\left(\mathrm{CO}_{2} \mathrm{e}\right)$ emissions between the baseline (typically traditional stoves) and the project (typically improved stoves). Quantifying these $\mathrm{CO}_{2} \mathrm{e}$ emissions requires estimates of three primary inputs: emission factors, fuel consumption, and the fraction of non-renewable fuel harvesting for biomass fuels (fNRB) $\left(\mathrm{CO}_{2}\right.$ from renewable harvesting is not counted as it is incorporated back into the biosphere), combined with an assessment of the number of stoves that are operational in the community. The Gold Standard method estimates carbon offsets as the difference in the product of fuel consumption and emission factors for the baseline and project scenarios, although stove specific emission factors are not required, with biomass fuel savings being apportioned into the non-renewable fraction. The CDM method estimates biomass fuel savings and applies an IPCC fossil fuel emission factor to the non renewable fraction of biomass fuel savings. Table 1 summarizes the approaches used to estimate the three primary inputs for $\mathrm{CO}_{2} \mathrm{e}$ savings. For which the Gold Standard and CDM methods rely heavily on proxy or default inputs without fully considering the impact of their uncertainty on offset estimates. An alternative approach presented in Johnson et al. (2009) has been added for comparison, which relies on representative statistical sub-sampling of emissions and fuel consumption in 


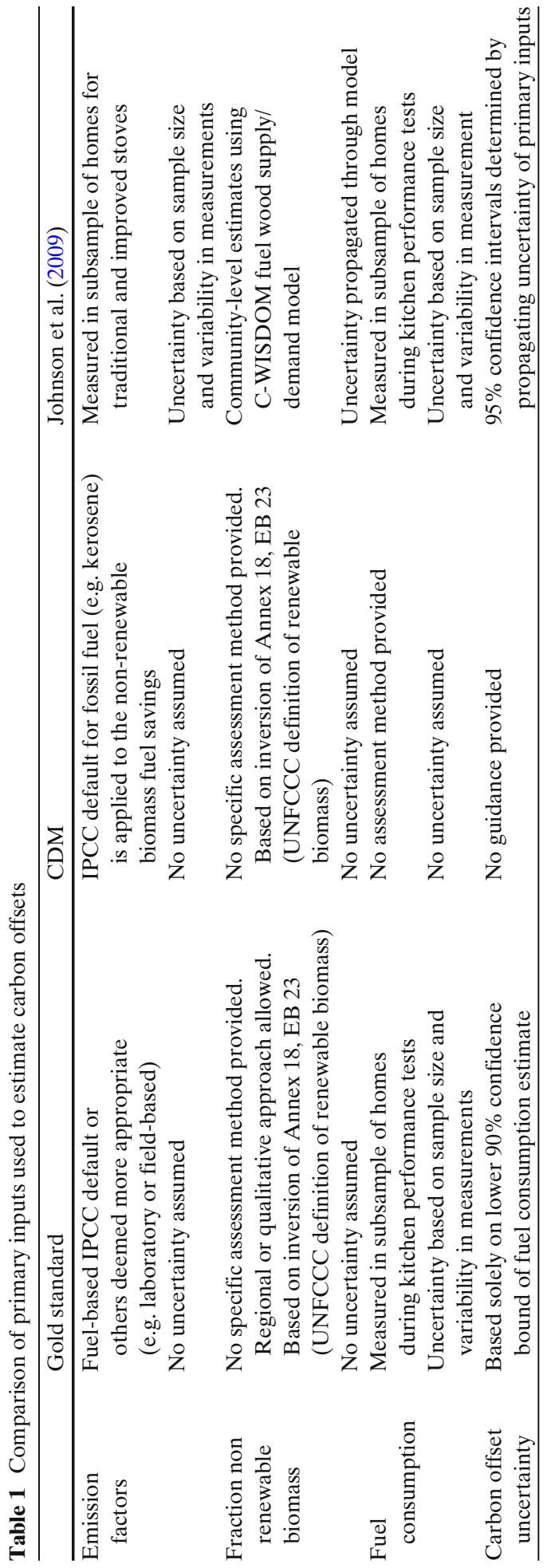


homes with traditional stoves and homes with improved stoves combined with local community estimates of $\mathrm{fNRB}$, and propagates the uncertainty inherent in these estimates to provide the overall uncertainty associated with estimation of carbon offsets in the larger community.

As stakeholder confidence in the validity of carbon offsets is the cornerstone of successful trading, full accounting of uncertainty in the offset estimates is crucial. The CDM method, however, makes no mention of uncertainty and the Gold Standard assumes no uncertainty in emission factors or fNRB. Using the Patsari cookstove stove project in Mexico for illustration (Masera et al. 2005), Fig. 1 demonstrates the differences in carbon offset estimates using standard methods in relation to estimates using community based sub-sampling. In addition, for comparison purposes uncertainty from using a regional spatially explicit estimate of fNRB $(0 \pm 18 \%$ standard error) and uncertainty associated with default emission factors recommended by IPCC Good Practice Guidance and Uncertainty Management in National Greenhouse Gas Inventories has been added to the Gold Standard and CDM methods in scenarios D and E. Incorporating the full uncertainty recommended in using default emission factors would therefore imply zero marketable offsets as the lower $95 \%$ confidence bound exceeds the amount of carbon saved. Even using uncertainty from only one of the factors, fuel consumption, results in marketable savings of only $0.42 \mathrm{tCO}_{2} \mathrm{e}_{\text {home }}^{-1}$ year $^{-1}$ using the Gold Standard approach in Scenario C. Incorporating local community based assessment of emission factors into the Gold Standard method increases the magnitude of carbon offsets by $70 \%$ (Scenario B). In Scenario A local community based sub-sampling of emission factors and fuel consumption combined with spatially explicit community based assessment of fNRB further increases the magnitude of the carbon offset, while incorporating realistic uncertainty bounds derived from local community estimates.

\subsection{Emission factors}

Use of fossil fuel emissions factors applied to the non-renewable fraction of fuel wood harvesting in the CDM methods has no scientific basis, given that wood (121 $\mathrm{tCO}_{2} \mathrm{e} \mathrm{TJ}{ }^{-1}$ ) emits approximately double the $\mathrm{CO}_{2}$ e per unit fuel energy compared to LPG $\left(63 \mathrm{tCO}_{2} \mathrm{e} \mathrm{TJ}{ }^{-1}\right)$ or kerosene $\left(72 \mathrm{tCO}_{2} \mathrm{e} \mathrm{TJ}^{-1}\right)$ (Gomez and Watterson 2006), thus halving possible offsets from non-renewable harvesting of fuel, while ignoring the non- $\mathrm{CO}_{2}$ emissions from renewable wood harvesting.

Use of IPCC default emission factors in the Gold Standard method also presents problems as the National Greenhouse Gas Inventory only presents broad ranges for $\mathrm{CH}_{4}\left(258-2,190 \mathrm{~kg} \mathrm{TJ}^{-1}\right)$ and $\mathrm{N}_{2} \mathrm{O}\left(4-18.5 \mathrm{~kg} \mathrm{TJ}^{-1}\right)$, and no emission factor for $\mathrm{CO}_{2}$, forcing a choice within these wide ranges or application of the discrete emission factors from the general category of "residential and agricultural/forestry/fishing/fishing farms." Even if the source data for these emission factors is referenced, these emissions factors were generated using water boiling tests in simulated kitchens, which do not reflect daily cooking activities (Johnson et al. 2008; Roden et al. 2006), leaving aside errors induced by applying emissions factors generated by stoves that

\footnotetext{
${ }^{1}$ Reported in Chapter 2, Table 2.5 of the 2006 IPCC Guidelines for National Greenhouse Gas Inventories (112000 $\mathrm{kg} \mathrm{CO}_{2} \mathrm{TJ}^{-1}, 300 \mathrm{~kg} \mathrm{CH}_{4} \mathrm{TJ}^{-1}, 4 \mathrm{~kg} \mathrm{~N}_{2} \mathrm{O} \mathrm{TJ}^{-1}$ ).
} 


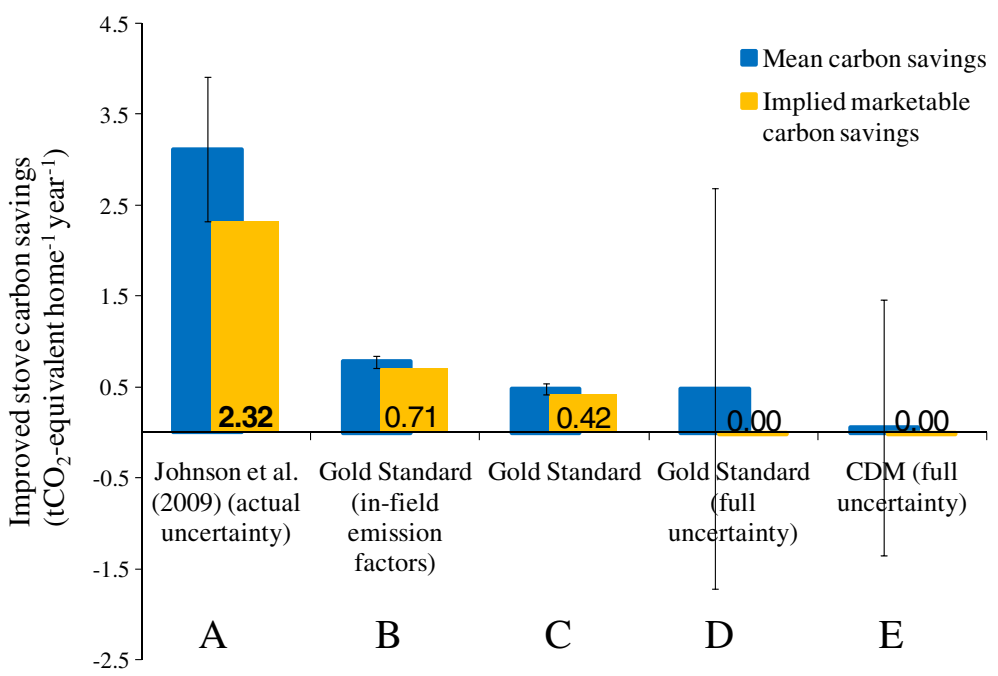

Fig. 1 Carbon offsets and corresponding 95\% confidence intervals when applying the Johnson et al. (2009), Gold Standard, and CDM methods to the Patsari Project. A C-WISDOM applied to project communities, field-based fuel consumption and emission factors (see Johnson et al. 2009); $95 \%$ confidence intervals incorporating uncertainty from all parameters. B Gold Standard method using national WISDOM for Purépecha region, field-based fuel consumption and emission factors (see Johnson et al. 2009); 90\% lower confidence bounds incorporating only fuel consumption uncertainty. $C$ Gold Standard method using national WISDOM for Purépecha region, field-based fuel consumption (see Johnson et al. 2009), IPCC default emission factors $\left(112,000 \mathrm{~kg} \mathrm{CO}_{2} \mathrm{TJ}^{-1}\right.$, $258 \mathrm{~kg} \mathrm{CH}_{4} \mathrm{TJ}^{-1}, 4 \mathrm{~kg} \mathrm{~N}_{2} \mathrm{OTJ}^{-1}$ ); $90 \%$ confidence intervals incorporating only fuel consumption uncertainty. $D$ Full uncertainty of Gold Standard method using National WISDOM for Purépecha region, field-based fuel consumption, IPCC default emission factors $\left(112,000 \mathrm{~kg} \mathrm{CO}_{2} \mathrm{TJ}^{-1}, 258 \mathrm{~kg}\right.$ $\mathrm{CH}_{4} \mathrm{TJ}^{-1}, 4 \mathrm{~kg} \mathrm{~N}_{2} \mathrm{OTJ}^{-1}$ ); 90\% confidence intervals incorporating uncertainty from national WISDOM, IPCC recommended uncertainty in emission factors $\left(95 \%\right.$ CIs as percent of mean: $\mathrm{CO}_{2}$ $7 \%, \mathrm{CH}_{4} 50 \%, \mathrm{~N}_{2} \mathrm{O} 90 \%$ ), and fuel consumption. $E$ CDM method using National WISDOM for Purépecha region, field-based fuel consumption, IPCC default emission factors for LPG $(63,100 \mathrm{~kg}$ $\mathrm{CO}_{2} \mathrm{TJ}^{-1}, 0.9 \mathrm{~kg} \mathrm{CH}_{4} \mathrm{TJ}^{-1}, 0.7 \mathrm{~kg} \mathrm{~N}_{2} \mathrm{OTJ}^{-1}$ ); $95 \%$ confidence intervals incorporating uncertainty from national WISDOM, IPCC recommended uncertainty in emission factors ( $95 \%$ CIs as percent of mean: $\mathrm{CO}_{2} 7 \%, \mathrm{CH}_{4} 50 \%, \mathrm{~N}_{2} \mathrm{O} 90 \%$ ), and fuel consumption

may have different combustion conditions to the stove in the project in question, and the highly variable combustion conditions associated with stove type, cooking practices, and fuel type across stove projects (Bhattacharya et al. 2002a, b; Smith et al. 2000; Zhang et al. 2000). Still a choice must be made as to which stove to select from those used to generate the IPCC default ranges. Figure 2 highlights the errors inherent in such approaches by demonstrating that $\mathrm{CO}_{2} \mathrm{e}$ emission factors vary by $43 \%$ across all wood stoves used to derive the IPCC default range, with the mean $\mathrm{CO}_{2}$ e emission factor $\left(1,810 \mathrm{gCO}_{2} \mathrm{e} \mathrm{kg}^{-1}\right)$ underestimating the highest emitting stove by $18 \%$.

Alternatively, sub-sampling of emission factors in homes during normal daily stove use, which has been conducted several times (Johnson et al. 2008; Kituyi et al. 2001; Ludwig et al. 2003; Roden et al. 2006), greatly increases accuracy and precision of carbon offsets by using technology and community specific emissions. For example, sampling emissions of 13 Patsari stoves in homes in the Mexican 


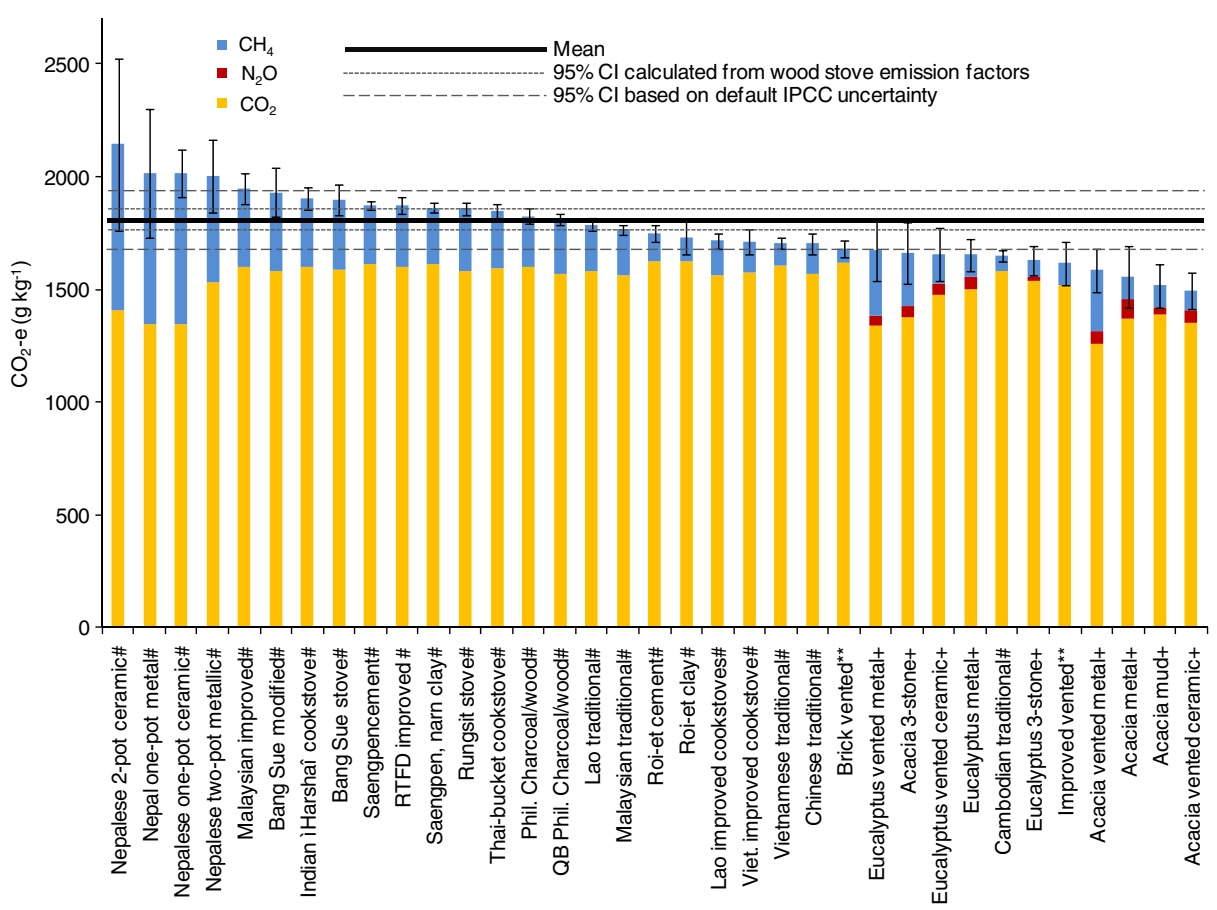

Fig. 2 Emission factors used to derive IPCC defaults for wood stoves. Notes: Error bars represent \pm 1 standard deviation. Recommended IPCC default uncertainty: $95 \%$ CIs as percent of mean: $\mathrm{CO}_{2}$ $7 \%, \mathrm{CH}_{4} 50 \%, \mathrm{~N}_{2} \mathrm{O} 90 \%$. The emission factors from Smith et al. (1993) are not included in the graph as uncertainty was not reported. \# Bhattacharya et al. (2002b). + Smith et al. (2000). * Zhang et al. (2000)

Meseta Purépecha resulted in a $\mathrm{CO}_{2} \mathrm{e}$ emission factor estimate with a $95 \%$ confidence interval of $1.0 \%\left(30 \mathrm{gCO}_{2} \mathrm{e} \mathrm{kg}^{-1}\right), 40 \%$ narrower than the $95 \%$ confidence interval of IPCC referenced emission factors $\left(50 \mathrm{gCO}_{2} \mathrm{e} \mathrm{kg}^{-1}\right)$, and 4.5 times narrower than the recommended default uncertainty ${ }^{2}$ of the IPCC referenced emission factors $\left(136 \mathrm{gCO}_{2} \mathrm{e} \mathrm{kg}^{-1}\right)$.

\subsection{Fraction non-renewable biomass harvesting}

Gold Standard and CDM approaches for estimating fNRB provide only a loose framework for estimation of fNRB. Even use of spatially explicit approaches to identify fuelwood hotspots at a national level (Masera et al. 2006; Top et al. 2004) lack sufficient resolution to characterize fuelwood consumption for specific communities - the functional scale required for small scale carbon offset projectssince they do not account for land ownership restrictions or local topography to identify where fuelwood is being harvested around a community. In addition, fNRB

\footnotetext{
${ }^{2}$ Recommended IPCC default uncertainty: $95 \%$ CIs as percent of mean: $\mathrm{CO}_{2} 7 \%, \mathrm{CH}_{4} 50 \%, \mathrm{~N}_{2} \mathrm{O}$ $90 \%$.
} 
estimates may vary widely between communities (Ghilardi et al. 2009) and thus significant errors may be incorporated in using regional estimates for a small number of communities typical of small scale improved stove projects. Non-spatially explicit or qualitative estimates should not be used as the uncertainty associated with these approaches would result in no carbon offsets using the lower $95 \%$ confidence interval to conservatively estimate offsets. Community level approaches such as C-WISDOM, in contrast, estimate fuelwood supply and demand by defining accessible areas from which residents obtain fuelwood with cost-distance maps, which reduces uncertainty by targeting the land cover impacted by the stove project (Ghilardi et al. 2009). In addition this approach allows targeting of stove projects to communities where fuelwood resources are scarce which tends to favor better adoption rates of the stove.

\subsection{Fuel consumption}

There is general agreement across current methods that fuel consumption must be directly monitored using the kitchen performance test, in which fuel is weighed in a subsample of homes. Although there are moves to replace in home testing with controlled cooking tests in simulated kitchens, controlled cooking tests may also not represent daily fuel use (Berrueta et al. 2008). The additional uncertainty incorporated by using this test and resultant reduction in carbon offsets likely outweighs any gains through reduction in field testing.

Additional fuel consumption monitoring would be warranted in areas with large seasonal or climatic variability, but gains in reduction of uncertainty should be balanced with increased costs of more extensive monitoring.

\subsection{Propagation of error}

The CDM method makes no recommendations in calculating uncertainty in the offset estimate, and the Gold Standard method only uses the lower $90 \%$ confidence bound of fuel consumption, ignoring uncertainty from emission factors and fNRB. Given that standard statistical approaches for propagating uncertainty from multiple inputs are readily available, such as those recommended in the Good Practice Guidance and Uncertainty Management in National Greenhouse Gas Inventories, assumption of no or unrealistically low uncertainty reflects poorly on the quality of the carbon offset. When the uncertainty is fully propagated through the computation for estimating the Patsari's carbon offsets in Purepecha communities, for example, fuel consumption contributed only $28 \%$ to the uncertainty in the offset estimate, while emission factors and fNRB contributed $25 \%$ and $47 \%$, respectively (Johnson et al. 2009). Though this distribution will differ across stove projects, the large contributions by emission factors and fNRB to offset uncertainty demonstrate that exclusion of this uncertainty is a critical omission. Even if not directly measured, IPCC gives recommendations for the uncertainty to be applied with use of emissions factors, and can be computed from input values for different methods to estimate fNRB. Perhaps more importantly, however, the significant contribution of all three inputs to the overall uncertainty highlights the importance of taking representative samples of these inputs. 


\section{Conclusions and recommendations}

Current standard methods may result in significant errors in the estimation of carbon offsets from improved stove projects. Equally critical, neither method incorporates the uncertainty inherent in estimates of emission factors or fNRB, which contributed $72 \%$ of the uncertainty in carbon savings for the Patsari cookstove (Johnson et al. 2009). Given these oversights, modification of current standard methods with methods based on local community sub sampling of emission factors and fuel consumption combined with spatially explicit community-level estimates of non-renewable fuel usage is warranted.

While local community sub-sampling methods require additional efforts in carbon offset estimation, they also likely result in substantially higher offset estimates that would defray additional expenditure (Fig. 1). The difference of $1.9 \mathrm{tCO}_{2} \mathrm{e}$ home $\mathrm{C}^{-1}$ year $^{-1}$ carbon savings between the Gold Standard method (scenario C) and using field-based community sub-sampling (scenario A) for instance, results in an additional US\$114,000 in implied marketable carbon savings for 2000 stoves assuming US\$7.5 $\mathrm{tCO}_{2} \mathrm{e}^{-1}$ over 4 years (Fig. 1). Given the financial sums involved in carbon offset purchasing, verifying the confidence in the estimate will become more critical, particularly in preventing unscrupulous practices. Simply because carbon offsets are made in rural areas of the developing world does not mean less vigorous carbon offset estimation approaches should be used. Given that resolution and quality of information from individual projects is likely to differ, however, valuation of $\mathrm{CO}_{2}-\mathrm{e}$ offsets based on the confidence bounds of the estimate provides a mechanism to promote better offset accountability. Such an approach would reward organizations marketing offsets where more time and energy has been committed to verifying estimates, without excluding those where such information gathering is limited, but may provide valuable areas for carbon reduction, especially given the potential cobenefits to health through reduction of air pollution. From a climate perspective, valuation of $\mathrm{CO}_{2}$-e offsets based on the confidence bounds of the estimate would promote better accounting that $\mathrm{CO}_{2}$-e savings from improved stove programs had actually been achieved.

Acknowledgements Our gratitude to the families from the Meseta Purépecha who opened their homes to us. Funding was provided by UCMEXUS-CONACYT Collaborative grant program, CONACYT Project 23640, and UNAM-PAPIIT Project IN109807.

Open Access This article is distributed under the terms of the Creative Commons Attribution Noncommercial License which permits any noncommercial use, distribution, and reproduction in any medium, provided the original author(s) and source are credited.

\section{References}

Berrueta VM, Edwards RD, Masera OR (2008) Energy performance of wood-burning cookstoves in Michoacan, Mexico. Renew Energy 33:859-870

Bhattacharya SC, Albina DO, Khaing AM (2002a) Effects of selected parameters on performance and emission of biomass-fired cookstoves. Biomass Bioenergy 23:387-395

Bhattacharya SC, Albina DO, Salam PA (2002b) Emission factors of wood and charcoal-fired cookstoves. Biomass Bioenergy 23:453-469

Climate Care (2008) Methodology for improved cook-stoves and kitchen regimes. Gold Standard, London 
Corre G (2007) Buyer beware of offsets that miss the mark. The Financial Times, London

Ghilardi A, Guerrero G, Masera O (2009) A GIS-based methodology for highlighting fuelwood supply/demand imbalances at the local level: a case study for Central Mexico. Biomass Bioenergy 33:957-972

Gomez DR, Watterson JD (2006) 2006 IPCC guidelines for national greenhouse gas inventories. Institute for Global Environmental Strategies, Kamiyamaguchi Hayama, Japan

Harvey F, Fidler S (2007) Industry caught in carbon 'smokescreen'. The Financial Times, London

IPCC (2000) Good practice guidance and uncertainty management in national greenhouse gas inventories. Intergovernmental Panel on Climate Change, Geneva

Johnson M, Edwards R, Alatorre Frenk C, Masera O (2008) In-field greenhouse gas emissions from cookstoves in rural Mexican households. Atmos Environ 42:1206-1222

Johnson M, Edwards R, Ghilardi A, Berrueta V, Gillen D, Frenk CA, Masera O (2009) Quantification of carbon savings from improved biomass cookstove projects. Environ Sci Technol 43:2456-2462

Kituyi E, Marufu L, Wandiga SO, Jumba IO, Andreae MO, Helas G (2001) Carbon monoxide and nitric oxide from biofuel fires in Kenya. Energy Convers Manag 42:1517-1542

Ludwig J, Marufu LT, Huber B, Andreae MO, Helas G (2003) Domestic combustion of biomass fuels in developing countries: a major source of atmospheric pollutants. J Atmos Chem 44:23-37

Masera OR, Diaz R, Berrueta V (2005) From cookstoves to cooking systems: the integrated program on sustainable household energy use in Mexico. Energy for Sustainable Development 9:25-36

Masera O, Ghilardi A, Drigo R, Trossero MA (2006) WISDOM: a GIS-based supply demand mapping tool for woodfuel management. Biomass Bioenergy 30:618-637

Roden CA, Bond TC, Conway S, Benjamin A, Pinel O (2006) Emission factors and real-time optical properties of particles emitted from traditional wood burning cookstoves. Environ Sci Technol 40:6750-6757

Smith KR, Khalil MAK, Rasmussen RA, Thorneloe SA, Manegdeg F, Apte M (1993) Greenhouse gases from biomass and fossil-fuel stoves in developing countries - a Manila pilot-study. Chemosphere 26:479-505

Smith KR, Uma R, Kishore VVN, Lata K, Joshi V, Zhang J, Rasmussen RA, Khalil MAK (2000) Greenhouse gases from small-scale combustion devices in developing countries. United States Environmental Protection Agency, Washington, DC

Top N, Mizoue N, Ito S, Kai S (2004) Spatial analysis of woodfuel supply and demand in Kampong Thom Province, Cambodia. Forest Ecol Manag 194:369-378

UNFCCC (2008) AMS-I.E: switch from non-renewable biomass for thermal applications by the user. UNFCCC, Bonn

Zhang J, Smith KR, Ma Y, Ye S, Jiang F, Qi W, Liu P, Khalil MAK, Rasmussen RA, Thorneloe SA (2000) Greenhouse gases and other airborne pollutants from household stoves in China: a database for emission factors. Atmos Environ 34:4537-4549 